\title{
Entre prácticas de intervención y proyectos de desarrollo: un acercamiento a los procesos organizativos indígenas en los valles interandinos (Salta, Argentina)
}

Between Intervention Practices and Development Projects: An Approach to the Indigenous Organizational Processes in the Inter-Andean Valleys (Salta, Argentina)

Entre práticas de intervenção e projetos de desenvolvimento: uma aproximação aos processos organizativos indigenas nos vales interandinos (Salta, Argentina)

María Paula Milana*

Emilia Villagra $^{* *}$

Recibido: 28 de enero de 2019

Aprobado: 10 de octubre de 2019

Doi: https://www.doi.org/10.12804/revistas.urosario.edu.co/territorios/a.7609

Para citar este artículo:

Milana, M. P., \& Villagra, E. (2020). Entre prácticas de intervención y proyectos de desarrollo: un acercamiento a los procesos organizativos indígenas en los valles interandinos (Salta, Argentina). Territorios, (42-Especial), 1-29. https://www.doi.org/10.12804/revistas.urosario.edu.co/territorios/a.7609

* Instituto de Investigaciones en Ciencias Sociales y Humanidades - Universidad Nacional de Salta - Consejo Nacional de Investigaciones Cientificas y Téenicas (ICSOH-UNSa-Conicet), Salta, Argentina. Correo electrónico: mpaulamilana@gmail.com. ORCID: https://orcid. org/0000-0001-9564-8763

* * Centro de Investigaciones y Estudios sobre Cultura y Sociedad - Universidad Nacional de Córdoba - Consejo Nacional de Investigaciones Científicas y Técnicas (CIECS-UNC-Conicet), Córdoba, Argentina. Correo electrónico: emivillagra93@gmail.com. ORCID: http://orcid. org/0000-0002-5639-7997 
Palabras clave

Organizaciones

indigenas, kollas, desarrollo, territorio qullamarka, derechos humanos.

Keywords

Indigenous organizations, Kollas, development, territory Qullamarka, human rights.

Palavras-chave Organizações indigenas, kollas, desenvolvimento, território qullamarka, direitos humanos.

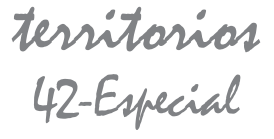

\section{RESUMEN}

El presente artículo indaga sobre procesos organizativos indígenas gestados entre los valles interandinos de la provincia de Salta (departamentos de Santa Victoria, Iruya y parte de Orán). Partiendo de la década de 1980, se propone una lectura de un conjunto de sucesos y experiencias que dan cuenta de cómo, a partir de la puesta en ejercicio de prácticas particulares de gobierno, vinculadas al discurso del desarrollo y los derechos humanos, se articularon un conjunto de actores provenientes de ámbitos heterogéneos - religiosos, estatales, no gubernamentales-, quienes intervinieron de manera singular en el surgimiento de organizaciones indígenas de segundo grado, autoadscriptas al pueblo kolla. El objetivo es identificar algunas condiciones de posibilidad que operaron en la consolidación de estas organizaciones y en sus singulares estrategias de lucha por el territorio, hasta lograr agruparse en una supraorganización de tercer grado en el año 2007.

\section{ABSTRACT}

This article explores indigenous organization processes developed between the inter-Andean Valleys of the province of Salta (departments of Santa Victoria, Iruya, and part of Oran). Starting in the 1980s, it proposes a reading on a set of events and experiences that show how, from putting into practice particular government practices linked to development discourse and human rights, a set of actors from heterogeneous spheres — religious, state, non-governmental-, who singularly intervened in the emergence of second-degree indigenous organizations, self-appointed to the Kolla people. The objective is to identify some conditions of possibility that operated in the consolidation of the organizations and their unique strategies of struggle for the territory until they grouped themselves in a third-degree supra-organization in 2007.

\section{RESUMO}

O presente artigo indaga sobre processos organizativos indígenas gestados entre os Vales interandinos da província de Salta (departamento de Santa Victoria, Iruya e Parte de Orán). Partindo da década de 1980, propõe uma leitura sobre um conjunto de acontecimentos e experiências que dão conta de como, a partir da execução de particulares práticas de governo vinculadas ao discurso do desenvolvimento e os direitos humanos, se articulou um conjunto de atores provenientes de âmbitos heterogêneos -religiosos, estatais, não governamentais-, intervindo de forma singular no surgimento de organizações indígenas de segundo grau, auto adscritas ao povo kolla. O objetivo é identificar algumas condições de possibilidade que operaram na consolidação destas organizações e em suas singulares estratégias de luta pelo território, até conseguir se agrupar em uma supra-organização de terceiro grau no ano 2007. 


\section{Introducción $^{1}$}

Concentrándose en las dos últimas décadas del siglo XX e inicios del XXI, el presente artículo indaga sobre los procesos organizativos indígenas gestados entre los valles interandinos. Este espacio se ubica en el noroeste argentino, al norte de la provincia de Salta (departamentos de Santa Victoria, Iruya y parte de Orán). Se extiende desde la precordillera saltojujeña al oeste, mediando un conjunto de valles de altura hasta las sierras subandinas o Andes tropicales al este. Suele incluirse en las cartografías de "tierras altas" y del Alto Bermejo (Reboratti, 2009) (figura 1).

Los valles interandinos constituyen intrincadas y extensas geografías, en las cuales la movilidad espacial de sus habitantes se ha caracterizado históricamente por viajes por sinuosos senderos y ríos de montaña. Desde los años ochenta, un conjunto de transformaciones socioespaciales repercutió abruptamente en las economías domésticas, las intervenciones en el territorio y la configuración de las subjetividades políticas. Se emplazaron nuevas escuelas y nuevos puestos sanitarios, se

Figura 1. Área de estudio. Valles interandinos de la Provincia de Salta (Argentina)

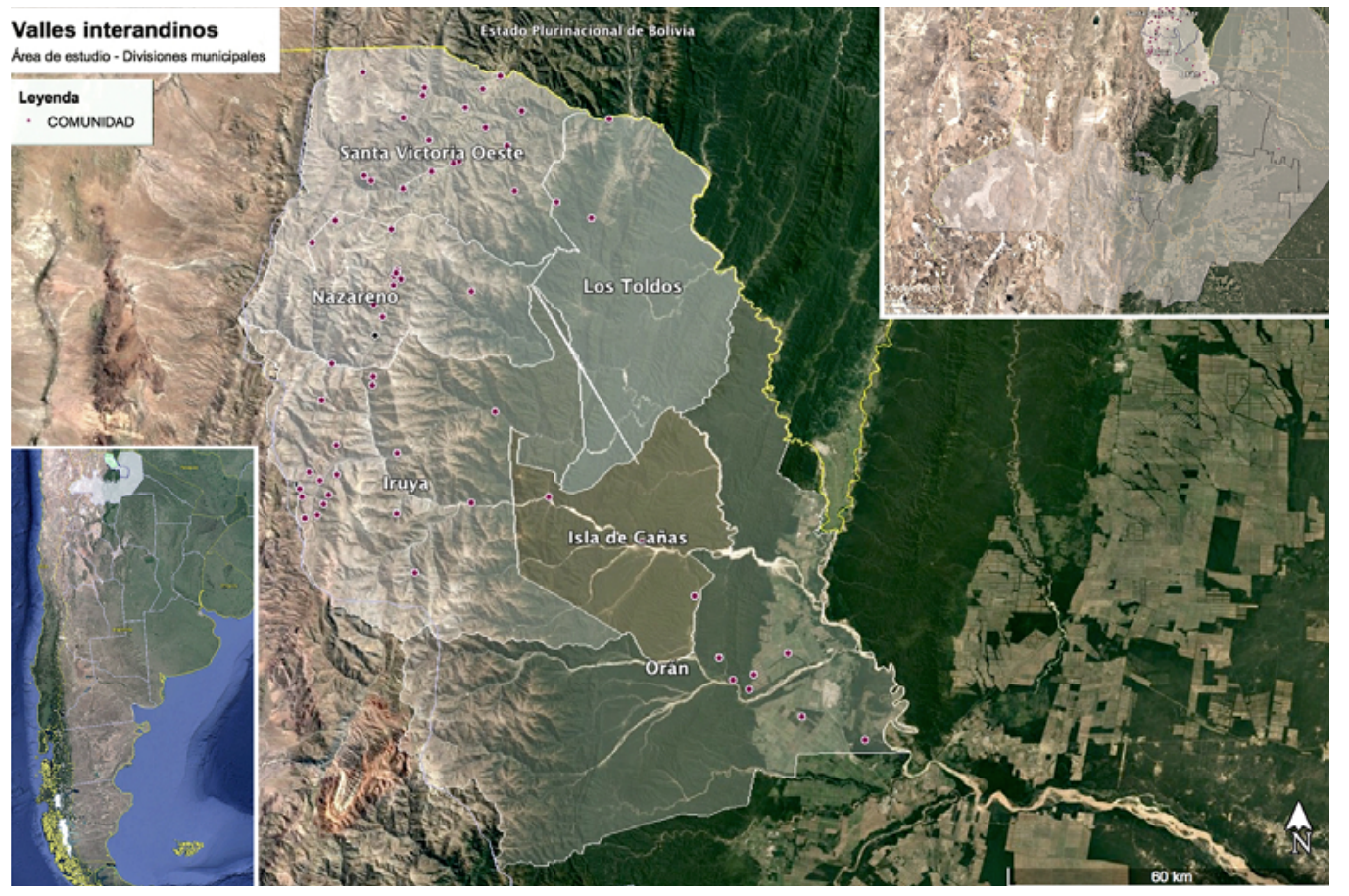

Fuente: elaborado a partir de imágenes de Google Earth ${ }^{\circledR}$.

tersitorion 42-Especial

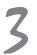

${ }^{1}$ En este texto utilizamos cursivas para referir expresiones nativas, mientras que empleamos comillas para retomar conceptos académicos, citas textuales o fragmentos de entrevistas. Sin embargo, aclaramos que a lo largo del articulo preservamos el anonimato y la confidencialidad de las voces de las y los líderes indigenas. 
${ }^{2}$ Siguiendo la terminología local, a lo largo del texto distinguiremos tres tipos de organizaciones. En primer lugar, las comunidades indigenas $u$ organizaciones "de base" o "de primer grado", que suelen contar con personería juridica reconocida por el Estado. Las organizaciones de "segundo grado" buscan representar a un conjunto de comunidades siguiendo criterios geográficos o jurisdiccionales, en algunos casos poseen personería. Finalmente, las organizaciones de "tercer grado" agrupan a más de una organización de segundo grado y se constituyen como coordinadoras o confederaciones.

\section{territorias 42-Especial}

abrieron caminos y se instalaron sistemas de energía eléctrica. Esto contribuyó a impulsar nuevos desplazamientos de personas al interior de cada departamento.

De esta manera, de la mano de una demografía estable, se incrementaron los procesos de intervención sobre las poblaciones de los valles interandinos. Una creciente cantidad de proyectos y programas de desarrollo en primera instancia y, un poco más tarde, una serie de capacitaciones en derechos humanos contribuirían a la formación de recursos humanos indígenas locales tales como animadores, promotores comunitarios, productores y técnicos idóneos, maestros y líderes indígenas.

En este entramado relacional, se generaron instancias y modalidades colectivas de trabajo que darían lugar — con dinámicas particulares en cada caso- a la articulación de un conjunto de comunidades de base o de primer grado que compartían una jurisdicción política o cercanía geográfica, que logró consolidar cinco organizaciones indígenas de segundo grado, agrupadas en la Comunidad Indígena del Pueblo Kolla Tinkunaku (CIPKT), la Asociación de Comunidades Aborígenes de Nazareno (OCAN), la Unión de Comunidades Aborígenes Victoreñas (UCAV), el Consejo Indígena Kolla de Iruya (CIKDI) y la Comunidad Indígena Alta Cuenca del Río Lipeo (CIACRL). La similar y estrecha pertenencia entre sus miembros, así como sus tácticas y estrategias variadas, habilitarían la posibilidad de enmarcar sus luchas en un frente común: la creación de una coordinadora indígena que las agrupa desde el 2007 y que ha logrado afianzarse como organización indigena de tercer grado, espacio de representación del pueblo kolla: Qullamarka, Coordinadora de Organizaciones y Comunidades Kollas Autónomas de Salta. ${ }^{2}$

El objetivo del trabajo es dar cuenta de cómo se entretejieron estas relaciones, identificando algunas condiciones de posibilidad que operaron en la emergencia y consolidación de estas organizaciones, a la par de indagar acerca del "campo de interlocución” (Briones \& Ramos, 2010) en el cual trazan alianzas y disputan demandas y reclamos colectivos. Nos interesa, desde esta lectura, aproximarnos a estos espacios y sus experiencias singulares de lucha, a través de las cuales interpelan, resisten o resignifican las prácticas y mecanismos de intervención, mediante memorias y saberes locales que proponen nuevos modos de habitar el espacio y de significar pertenencias e identificaciones políticas.

En términos epistemológicos y metodológicos, retomamos la perspectiva etnográfica para poner de relieve las voces de los integrantes de las organizaciones indígenas, apostando a la construcción de la teoría desde la praxis política de los movimientos de grupos subalternos (Escobar, 2003), por medio del reconocimiento del lugar teórico y metodológico protagónico de nuestros interlocutores (Guber, 2011). Guiamos esta perspectiva con algunas herramientas analíticas que 
ofrece la "genealogía" (Foucault, 1992; 2000 ) para abordar la emergencia de este conjunto de eventos teniendo en cuenta su historicidad y las relaciones de poder en las que se entraman saberes, discursos y sujetos singulares. La genealogía busca exponer "saberes sometidos" — contenidos históricos relegados, saberes singulares y locales, descalificados o considerados inferiores- $-\mathrm{y}$ contrastarlos con discursos que operan de manera "deseventualizante" (Restrepo, 2008, p. 124). Este abordaje permite dar cuenta de la consolidación de subjetividades políticas subalternas y articulaciones territoriales en los valles interandinos, con mutaciones hasta el presente. Asimismo, sin dejar de prestar atención a la forma en que operan las prácticas de gobierno multiculturales y neoliberales, permite indagar cómo las comunidades y organizaciones indígenas producen el "espacio social" (Lefebvre, 2013).

Este trabajo forma parte de nuestras investigaciones doctorales, las cuales buscan aportar al conocimiento de los procesos organizativos del pueblo kolla en los valles interandinos y a la visibilización de sus luchas. Desde un abordaje cualitativo, basado en el trabajo de campo emprendido desde el 2012 hasta la actualidad, hemos realizado entrevistas abiertas y semiestructuradas, participamos en las asambleas de las organizaciones indígenas, asistimos a talleres de capacitación en agricultura y ganadería, comunicación, género y derechos humanos, y ejecutamos proyectos de extensión universitaria y de comunicación social (Milana, 2014; Villagra, 2016; Milana \& Villagra, 2018; Villagra \& Milana, 2019). El análisis también se nutre del material producido por las propias organizaciones: actas históricas, proyectos de desarrollo, revistas y cartografías.

El artículo se estructura de la siguiente forma: en diálogo con la lucha de las organizaciones indígenas en Salta, en el primer apartado referimos las características de la estructura agraria en los valles interandinos y el denominado por sus habitantes como tema territorio. En el segundo, reconstruimos un momento previo a la emergencia de las organizaciones kollas, poniendo el foco en el accionar de actores religiosos y estatales desde el retorno democrático en 1983 hasta 1994, año en que se reformula la Constitución de la Nación Argentina. El tercer apartado indaga las instancias de conformación de organizaciones indígenas de segundo grado desde fines de la década de 1990 y principios del 2000, para lo cual retomamos reuniones, marchas y pronunciamientos, así como la relación establecida con agentes gubernamentales a través del Programa Social Agropecuario (PSA). El cuarto apartado se concentra en la coyuntura previa al surgimiento de la organización de tercer grado. A modo de cierre, reflexionamos sobre cómo estas prácticas singulares llevaron a una vinculación de actores con motivaciones y trayectorias heterogéneas que, aunque dentro de campos discursivos comunes — como el del desarrollo y los derechos
${ }^{3}$ Foucault (2000) define la investigación genealógica como una apuesta por "la reactivación de los saberes locales” (p.24) y como un combate contra los efectos de poder de los discursos hegemónicos -enfatizando en los saberes cientificos-y su pretensión de descalificar otras formas discontinuas del saber.

territarias 42-Especial 
${ }^{4}$ Las experiencias de organización indigena de las últimas décadas del siglo XX en Argentina han sido problematizadas desde conceptos como "etnogénesis", "reetnización” (Radovich \& Balazote, 1992) o "aboriginalidad" (Briones, 1998), entre otros.

${ }^{5}$ El Convenio 169 de la OIT, ratificado en Argentina en 1992 (Ley 24071), reconoció a los pueblos indigenas como titulares de derechos colectivos cuyas "prioridades de desarrollo" deben ser promovidas y protegidas por el Estado. La incorporación en 1994 del artículo 75 inciso 17 en la Constitución Nacional, además de reconocer su preexistencia étnica y cultural, sentó el deber de reconocer "la posesión y propiedad comunitaria de las tierras que tradicionalmente ocupan; y regular la entrega de otras aptas y suficientes para el desarrollo bumano”.

\section{territorias 42-Especial}

humanos - y en el marco de relaciones sociales y espaciales históricas, contribuyeron a la redefinición de las arenas políticas donde pueden librarse las luchas por el territorio de los valles interandinos.

\section{El problema de la tierra y la lucha por el territorio}

Desde 1983, con el advenimiento de la democracia en Argentina, múltiples experiencias de organización política indígena se visibilizaron en la arena pública, haciéndose eco de una demanda que, en gran parte de los casos, continúa sin resolución: la recuperación de las tierras habitadas y la regularización de los títulos de propiedad comunitaria. La irrupción de colectivos autoadscriptos a gentilicios, que referían a pueblos indígenas considerados extintos, desaparecidos o mestizados, puso en perspectiva la narrativa nacional hegemónica sobre la "cuestión indígena" en el país, dando cuenta de sentidos de pertenencia de lo que fue denominado como "indigenidades emergentes" (Gordillo \& Hirsch, 2010). ${ }^{4}$

$\mathrm{Al}$ igual que en gran parte de América Latina y al compás de la progresiva ratificación de instrumentos internacionales de derechos humanos de pueblos indígenas, en Argentina se canalizaron programas, proyectos y créditos de financiamiento internacional dirigidos a las poblaciones rurales e indígenas, coherentes con una resignificación del discurso del desarrollo humano. ${ }^{5}$ En esta dirección, las organizaciones han librado - y lo hacen aún en el presente- sus luchas en escenarios que responden al "multiculturalismo neoliberal" (Hale, 2004) donde, aún disponiendo de legislaciones favorables al reconocimiento de los pueblos indígenas, las situaciones de conflictividad territorial continúan agudizándose.

En Salta, provincia cuyas narrativas identitarias han gravitado sobre el atributo de la "salteñidad" (Lanusse \& Lazzari, 2005; Álvarez Leguizamón \& Muñoz, 2010), la presencia indígena ha sido poco visibilizada a pesar de su relevancia. En comparación con el porcentaje nacional de personas autoidentificadas como indígenas o sus descendientes, poco más del $2 \%$, la provincia registra un $6,6 \%$ respecto de la población total provincial, es decir 79204 personas (INDEC, 2010). A su vez, Salta es una de las provincias con mayor diversidad de población indígena del país, cuenta con nueve pueblos indígenas hoy reconocidos por el Estado provincial: kolla, diaguita, chané, chorote, chulupi, guarani, tapiete, toba y wichi (Buliubasich, 2013). Otros cinco continúan reclamando reconocimiento: lule, tastil, atacama, iogys y weenhayek.

En las últimas décadas, el aumento del valor de las tierras y su degradación ha perpetuado la reproducción de condiciones de exclusión y subordinación histórica, que potencian la inseguridad jurídica sobre los territorios de las poblaciones indígenas y multiplican las situaciones de desalojo. Desde fines de los años ochenta, los 
reclamos, demandas y acciones colectivas en defensa de los territorios adquirieron visibilidad pública, disputando no solo la propiedad de las tierras, sino también la autonomía y el control de los recursos (Sabio \& Milana, 2018).

El hecho de ser una de las provincias con mayor concentración de la tierra en manos extranjeras, empresas privadas y unas pocas familias remite a un conflicto por la propiedad asentado sobre procesos históricos de larga data. Esto se inscribe en una configuración social de matriz neocolonial, históricamente orientada a la apropiación y concentración de grandes superficies de tierra por parte de sectores sociales dominantes que conformaron la elite local, señalando a los grupos indígenas como ocupantes y usurpadores, para despojarlos de sus lugares de vida (Álvarez Leguizamón, 2015).

De tal forma, las particularidades que componen nuestro caso de estudio se refieren a espacios de ocupación y convivencia de sociedades indígenas que, desde la época colonial, fueron apropiados mediante mercedes reales o encomiendas otorgadas a españoles y sus descendientes. Esto sentó las bases para concentrar diferentes extensiones de tierras en las llamadas haciendas. Desde el siglo XIX, muchas de estas disposiciones devinieron en lo que actualmente se conoce como fincas, algunas legitimadas como propiedades privadas, mientras que otras fueron expropiadas por concepto de tierras fiscales de los gobiernos independientes provinciales y nacionales
(Reboratti, 2009). En este contexto, los pueblos indígenas, imposibilitados de gozar de un estatuto o legislación particular que los reconociera como dueños de las tierras habitadas, pasaron a ser considerados como "ocupantes" y "usurpadores".

Ejemplos de estas disposiciones son Finca San Andrés (en el actual departamento de Orán), Finca Santiago (en el actual departamento de Iruya) y Finca Santa Victoria (actual departamento de nombre homónimo), entre otras de menor extensión como Finca Los Toldos. Las tierras de estas tres últimas fueron integradas desde la colonia al marquesado de Tojo o de Yavi, dominio extendido entre los valles interandinos, la Puna jujeña y el sur boliviano. ${ }^{6}$ En 1883 las posesiones del marquesado quedaron divididas entre familias herederas en Argentina y Bolivia. Si bien la mitad de estas extensiones se redujo debido a expropiaciones en la $\mathrm{Pu}$ na jujeña, los descendientes del marqués conservaron dos importantes haciendas en el sector argentino: Yavi y Santa Victoria. Recién a fines del siglo XIX, la legitimidad de los títulos del marquesado fue cuestionada, lo que generó conflictos tanto con otros propietarios como con comunidades indígenas (Teruel, 2016).

Avanzado el siglo Xx, extensos territorios de los valles interandinos fueron adquiridos por el ingenio San Martín del Tabacal, fundado en 1920 en el departamento de Orán. Uno de sus principales dueños, Robustiano Patrón Costas, adquirió en 1930 la Finca San Andrés y la
${ }^{6}$ El origen del marquesado se vincula con mercedes de tierra otorgadas luego de la fundación de Tarija (sur de Bolivia) a finales del siglo XVI, la posesión de una importante encomienda -Casabindo y Cochinoca-, el montaje de una empresa abastecedora de productos para las minas del Potosi y la anexión de propiedades a lo largo de dos siglos. Como tal, el titulo nobiliario fue concedido por la corona española a Fernández Campero y a su muerte se inició el mayorazgo de Tojo, el cual existiría por varias generaciones hasta que el cuarto marqués fuera tomado prisionero por los españoles, confiscados sus bienes y exiliado a España. El hijo de este, Fernando Campero Barragán (1809-1883), fue el último propietario del mayorazgo (Teruel, 2016; Reboratti, 2009).

\section{territorias 42-Especial} 7 
${ }^{7}$ La palabra zafra hace alusión a la recolección de la caña de azúcar y se realiza durante determinadas épocas del año, generalmente desde noviembre hasta abril.

${ }^{8}$ Se trató de una caravana de grupos kollas hacia Buenos Aires, en reclamo de sus tierras, abordada como inicio de la "primera fase del movimiento indigenista en la Argentina” (Gordillo \& Hirsch, 2010, p. 24).

\section{territorias 42-Especial}

Finca Santiago - devenidas tierras fiscales luego de la independencia-y arrendó la Finca Grande de Santa Victoria hasta mediados de siglo, con el fin principal de acceder de forma coactiva a mano de obra barata en los periodos estacionales de zafra. ${ }^{7}$ La formación del mercado de trabajo se estructuró en concordancia con esta agroindustria, que urgía por trabajadores estacionales y que comenzó a incorporar compulsivamente a grupos indígenas de los valles salto-jujeños y de la Puna desde la década de 1930 (Campi \& Lagos, 1995). El hecho de convertirse en zafreros temporarios y arrendatarios tuvo efectos en la economía local, condicionada por un ciclo de trabajo que se superponía al trabajo agrícola y de pastoreo. Las migraciones estacionales obligadas hasta mediados del siglo Xx condujeron a un gran abandono de los pisos de cultivo y de ciertas variedades locales.

El caso de la Finca Santa Victoria es paradigmático: los Campero, descendientes del marqués, alquilaron las tierras al ingenio San Martín desde 1930 hasta 1960, y obligaron a los habitantes a trabajar en él sin recibir dinero a cambio, con el argumento de que su fuerza de trabajo equivalía al pago que debían abonar por la parcela de tierra que ocupaban, es decir, por su condición de subarrendatarios (Madrazo, 1982; Reboratti, 2009). A mediados de siglo, los pobladores comenzaron a emprender acciones colectivas para recuperar las tierras, como el Malón de la Paz de $1946 .^{\circ}$ Ante la creciente negación de continuar pagando el arriendo, la familia Campero cedió el sector con menor productividad de la finca a los pobladores mediante boletas de compraventa ilegales. Este mecanismo, operativizado a través del administrador de la finca y el contratista del ingenio, implicaba presionar y amenazar a los pobladores para que compraran terrenos; esto ejemplifica la persistencia de relaciones de poder sobre la continuidad de los pagos y el trabajo en el ingenio. Por otro lado, la zona baja o de yungas fue vendida a un obraje (Reboratti, 2009, pp. 176-178).

Esta recapitulación permite enmarcar algunos antecedentes históricos y simbólicos de las luchas del presente. El inacceso a los derechos de propiedad y la perduración de extensas fincas en los valles interandinos, cuyos títulos se busca recuperar, han implicado resignificar la lucha a través de memorias y experiencias compartidas de dolor e injusticia sobre el arriendo y el trabajo en los ingenios, que permite hilar continuidades con las experiencias organizativas actuales. En este complejo proceso de relaciones de poder paradigmáticas se sustenta el proyecto político de la organización Qullamarka. En este marco, y debido a la falta de títulos de propiedad de las tierras -inicial aglutinador de los reclamos-, el "territorio indígena" o territorio Qullamarka puede ser definido como el espacio poblado, defendido y resignificado como entorno de modos de vida propios, anclaje de ocupación continua e histórica de las poblaciones 
locales. Por ello, las organizaciones indígenas del Qullamarka, plantean que, en la heterogeneidad de sus colectivos, la lucha por el territorio y la identidad kolla es un denominador común.

\section{Agentes, instituciones y políticas rurales de "desarrollo"}

A partir del retorno democrático en Argentina, en 1983, la agenda social del Estado se modificó en función de la creación de nuevos dispositivos de intervención. En los valles interandinos se pusieron en marcha diferentes programas y proyectos orientados a gestionar la "pobreza" de las poblaciones rurales, permeados por un discurso del desarrollo cada vez más humanizado (Álvarez Leguizamón, 2008).

El programa de Atención Primaria de la Salud (APS), implementado durante la última dictadura militar (1976-1983), continuó formando "agentes sanitarios" que debían monitorear la población y promover hábitos de higiene y prevención de enfermedades que permitieran avanzar hacia "niveles más dignos de salud y bienestar" (Marco Doctrinario APS, citado en Quiroga Mendiola et al., 2006, p. 393)..$^{9}$ Ello implicaba censar las poblaciones y sus condiciones económicas y sanitarias, y controlar embarazos, índices de desnutrición y crecimiento infantil. Los agentes no solo debían visitar los parajes más lejanos y concientizar sobre prácticas, saberes de higiene y salud pública, también informaban sobre planes y ayudas sociales para las familias carenciadas (Torres \& Torres, 2010).

Estas visitas o rondas sanitarias se realizaban en función de sectores de trabajo delimitados, los cuales eran subdivididos a medida que se producía un conocimiento más específico del espacio y los habitantes. Ello posibilitó confeccionar cartografías regionalizadas y demandar mayor cantidad de profesionales para las comunidades. Estas colaboraban con mano de obra para la construcción de los puestos sanitarios, los cuales, además, eran equipados con un sistema de radiocomunicación.

La figura 2 ilustra la implementación del dispositivo en el departamento de Iruya, parte de nuestra zona de estudio. Allí pueden observarse los caminos con acceso carretero, la localización del hospital y la distancia en horas desde este a los puestos sanitarios que cubrían a las distintas comunidades en el año 2008.

En la figura 3, al igual que en la anterior, puede observarse la disposición de puestos sanitarios en conexión con el hospital central, con el objetivo de cubrir la totalidad de la extensión de Nazareno.

Un grupo de agentes sanitarios formado en el programa también fue capacitado por la Prelatura de Humahuaca, provincia de Jujuy, con injerencia religiosa en los departamentos de Santa Victoria e Iruya. Cabe destacar que la Prelatura fue creada en 1969, a través de una bula papal. Concebida a modo de diócesis, con autonomía y bajo las órdenes de un Obispo - en ese momento era Márquez Bernal-, la
${ }^{9}$ El primer esquema de este programa fue implementado en 1978, cuando se denominaba Programa de Salud Rural y solo cubría los espacios con los indicadores socioeconómicos y sanitarios más alarmantes de la provincia; a partir de 1983, se integró al sistema de salud provincial (Torres \& Torres, 2010).

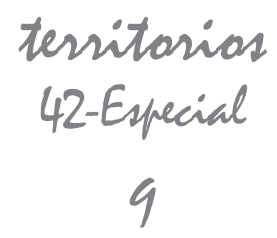


Figura 2. Cobertura del Programa de APS según origen, régimen horario y modalidad de contratación. Departamento de Iruya, Municipio de Iruya (área operativa VI)

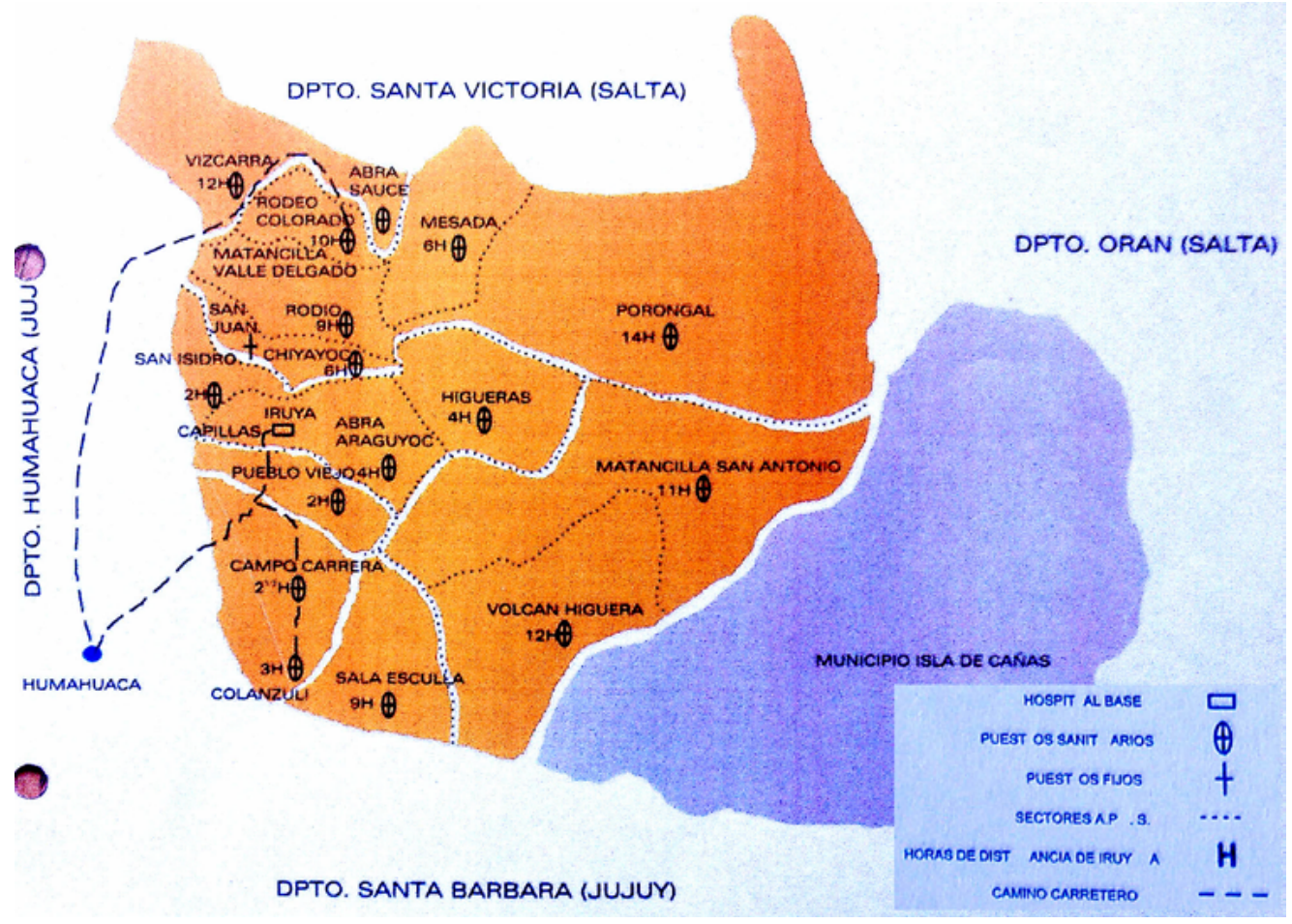

Fuente: Torres y Torres (2010).

jurisdicción eclesiástica abarcaba la Quebrada de Humahuaca y Puna de Jujuy. A partir de 1972, dicha jurisdicción se amplió para incluir los departamentos salteños de Santa Victoria e Iruya (Olmedo Rivero, 2004).

Enmarcada en la Prelatura, la Obra Claretiana para el Desarrollo (Oclade) se conformó en 1983 como una fundación sin ánimo de lucro, integrada por misioneros claretianos: mujeres y hombres comprometidos con la corriente social de la iglesia y la perspectiva del desarrollo humano. En general, los encuentros y programas de la prelatura estaban a cargo de Oclade, que comenzó a gestionar y concretar diversos proyectos desde lógicas de "promoción y organización comunitaria" (Torres \& Torres, 2010, p. 119) financiados a través de programas de cooperación internacional de Europa. Su fin último era lograr la "promoción humana" en el norte del país, zona considerada de "extrema pobreza” y exclusión económica y 
Figura 3. Cartografía de área operativa $X$, Nazareno (Santa Victoria Oeste), Salta. Programa de Enfermería, Hospital de Nazareno

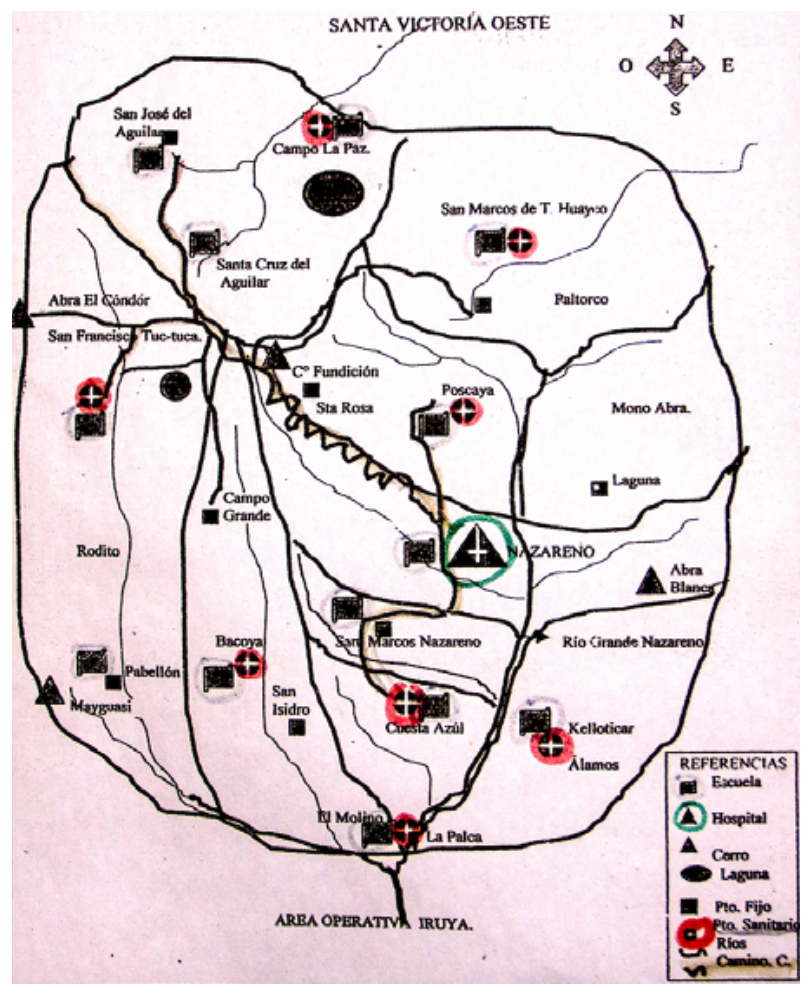

Fuente: fotografía tomada en la oficina territorial de la Subsecretaría de Agricultura Familiar, municipio de Nazareno, agosto de 2014.

social, con características adversas como el "aislamiento" y una "cultura del silencio" (Eizayaga, 1 de febrero de 2015).

Acentuando la condición étnica de las poblaciones de su jurisdicción, la prelatura propuso contribuir al fortalecimiento y la revalorización de las pautas culturales locales, lo cual podría lograrse desde la evangelización y la obtención de recursos. Se sostenía que los saberes religiosos debían abordar la realidad e incentivar la participación plena de las poblaciones pobres en el funcionamiento de la institución, "que las personas no sean un objeto de la acción y sí partícipes de los procesos que deriven en oportunidades de desarrollo" (Pedro Olmedo, citado en Agenda Pública, l de diciembre de 2008).

Este modelo evangelizador contemplaba entre sus dispositivos pedagógicos, además de los promotores sociales — profesionales que asesoraban y guiaban las tersitorios 42-Especial 


\section{tersitorias} 42-Especial iniciativas, sin necesario vínculo cercano con la comunidad-, la formación de personas de las comunidades que debían predicar y dar catequesis en su localidad: los "animadores". "Oclade siempre trabajó con los animadores, los animadores de repente eran de cada comunidad, impulsores de la "palabra de Dios" [...] Siempre se trabajó por intermedio de los animadores, como hoy hacemos con las autoridades de las comunidades» (lideresa indígena de Iruya, extrabajadora de Oclade, entrevista, abril de 2013).

Los animadores eran capacitados para formular y gestionar diversos proyectos luego de obtener el consenso de la comunidad, que generalmente debía colaborar con mano de obra. Estos proyectos abarcaban campos asociados a lo productivo, la infancia, la mujer y la comunicación. Se llevaban adelante programas de alfabetización, proyectos de construcción de capillas y salones comunitarios, pequeñas obras de canalización de agua para riego y agua potable a domicilio, invernaderos, alambrados y caminos carreteros, junto a iniciativas destinadas específicamente a la "mujer rural" tales como refacción de viviendas, cocinas, baños, y las líneas de microcrédito (Informe Final del Proyecto Kay Pacha, 2010). Las posibilidades de financiamiento se daban a conocer durante los encuentros zonales, es decir, reuniones periódicas de miembros de Oclade y otras instituciones participantes.

A pesar de tratarse de proyectos cuyo objetivo era mejorar las condiciones de vivienda y autoconsumo de las personas, se encontraban limitados por lo abordado en el apartado anterior: el problema de la tierra y la falta de los títulos de propiedad. Los habitantes no podían realizar mejoras sin ver encarecidos los arriendos. En otros casos, aunque ya no se pagaba arriendo, estas mejoras estaban prohibidas. En palabras de un dirigente de Iruya:

El gran problema que teníamos nosotros, era el tema territorio. No podíamos hacer ningún tipo de mejora, no podíamos no sé... mejorar el tema del tanque, el tema de los canales de riego, mejorar los caminos porque el territorio que estábamos ocupando no era nuestro (líder indígena de Iruya, exFinca Santiago, entrevista, diciembre de 2012).

Las limitaciones de estos programas también fueron puestas de relieve en las movilizaciones emprendidas a fines de la década de los ochenta. Aquí se detectan instancias de reclamo territorial en las zonas vecinas de Finca Santiago (Iruya) y Finca San Andrés y Santa Cruz (Orán), cuando la decisión de dejar de pagar arriendo ya había sido consensuada entre los habitantes y se emprendían estrategias para recuperar la propiedad de sus tierras. Uno de los hitos fundamentales fue la caravana de pobladores kollas de Orán en 1987, rumbo a la ciudad de Salta con el acompañamiento de la Asociación Indígena de la República Argentina (AIRA), la organización de las Segundas 
Jornadas por la Tierra en 1989, junto a habitantes de la Finca Santa Victoria y Finca Santiago (González, 2013; Sabio Collado \& Milana, 2018). ${ }^{10}$

En Nazareno, Oclade impulsó en 1987 un equipo zonal integrado por un pequeño grupo de personas, encargado de formular y gestionar proyectos locales para promover el desarrollo de la zona y litigar por sus tierras. A través del asesoramiento de Oclade, en articulación con el Equipo $\mathrm{Na}$ cional de la Pastoral Aborigen (Endepa) ${ }^{11}$ se plantearon dos posibilidades para el litigio: reclamos particulares (derecho veinteñal) o demandas colectivas por la propiedad comunitaria. Con el tiempo, la segunda opción fue elegida como válida para continuar la lucha por el territorio (Actas de OCAN, 1999-2004).

En el marco de una política de profundización neoliberal y de reasignación de las responsabilidades sociales del Estado nacional argentino al mercado, a las provincias u organizaciones no gubernamentales, la agudización de los conflictos territoriales suscitados por la presión extractiva en los valles interandinos (empresas forestales, de hidrocarburos, agrarias) contribuyó a una reconfiguración socioespacial. El incremento de amenazas de desalojo en territorios indígenas y la pérdida de fuentes laborales, en muchos casos, desembocó en el "retorno al territorio", de acuerdo con lo enunciado por un líder indígena de la organización Tinkunaku:
Esa misma gente que había descuidado durante quince años su casa, sus puestos, sus vacas, todo, cuando el ingenio [San Martín del Tabacal] les echa vuelve a la comunidad (...) y esta gente por menos ( sic) tuvo la posibilidad de volver, aunque sea a levantar el rancho, a sembrar o a levantar la pirca. Y ahí vieron la importancia y ahí toma uno más conciencia de lo que era el territorio, de lo que era la comunidad (líder indígena de Orán, asamblea del Qullamarka, agosto de 2014).

En 1991, los municipios de los valles interandinos encabezaban los índices más altos de pobreza en términos de necesidades básicas insatisfechas (NBI): Iruya $(79,1 \%)$, Santa Victoria $(68,6 \%)$ y Nazareno $(55,7 \%)$ (INDEC, 1991). A raíz de esto, Oclade manifestó a través del padre Pedro Olmedo su preocupación por la situación del país, los alarmantes datos de desocupación por el cierre de fábricas y empresas privadas y la agravada condición de "pobreza estructural" en estos espacios a causa de la ausencia del Estado argentino. El reconocimiento hacia esta figura pastoral y su discurso se plasmó en la gestión de la prelatura con recursos provenientes de ámbitos estatales y privados para la ejecución de diversos proyectos. Oclade, luego de implementar un programa llamado Promoción de la Mujer en la Puna, creó en 1992 el Programa Yachay: Desarrollo y Educación Infantil en Comunidades Collas, organizando un sistema de atención sanitaria periódica
${ }^{10}$ El caso del pueblo kolla de las exfincas San Andrés y Santa Cruz adquirió mayor visibilidad en el marco de los conflictos con el ingenio San Martín del Tabacal y el repudio a la construcción de un gasoducto en su territorio. Esto tuvo como una de sus principales estrategias la alianza con las ONG Greenpeace y Yaguareté, hasta obtener los titulos de gran parte de su territorio en 2007 (Dominguez, 2008; González, 2013). Otro caso documentado remite a la lucha de las comunidades kollas de Finca Santiago, cuyo titulo comunitario fue uno de los primeros del pais en ser restituido a sus pobladores en 1998 (Hocsman, 1997; Weinberg, 2004; Cladera, 2006).

${ }^{11}$ La Prelatura de Humabuaca se integró a Endepa en 1987. Nueve años más tarde, el Obispo de la Prelatura, Pedro Olmedo, fue nombrado presidente de aquella organización (Olmedo Rivero, 2004, pp. 156-157).

\section{territorios 42-Especial}


${ }^{12}$ En 1999, Oclade delegó el programa a los municipios $y$ al Instituto Nacional de Tecnología Agropecuaria (INTA), lo cual implicó el cambio de su orientación integral hacia una más técnica (Gaspar é Pineda, 2012).

${ }^{13}$ Según Occhipinti (2015), este "discurso de moralidad y justicia" no evita el hecho de que se hayan empleado "berramientas estándar de desarrollo" (p. 15), como los tipos de proyectos mencionados en párrafos anteriores.

\section{territarias 42-Especial}

(Olmedo Rivero, 2004, p. 149). En esta década, la Prelatura también accedió a fondos de la Secretaría de Desarrollo Social de la Nación, destinados a crear y sostener cincuenta comedores infantiles en su radio de intervención, que quedaron a cargo de "organizaciones comunitarias". Estos comedores continuaron creciendo hasta alcanzar casi un centenar en 2004.

Ello se sumaba a una serie de iniciativas para potenciar los conocimientos y saberes locales en el ámbito de las prácticas de autosubsistencia como el programa de Agentes de Producción Animal (APA). Este buscaba capacitar a las personas de las comunidades en actividades similares a las de un agente sanitario, en este caso desde el conocimiento veterinario, para poder realizar visitas domiciliarias, censos de animales, vacunación y promoción de formas de cuidado y crianza. El mismo programa había sido impulsado en 1985 por Oclade en Iruya, a modo de "alternativa andina de desarrollo local" (Torres \& Torres, 2010, p. 72). Luego sería replicado en otras comunidades de la puna jujeña, mientras que en el departamento de Santa Victoria oeste estaría a cargo del hermano Manuel, de la prelatura, quien desde 1991 trabajó junto a un grupo de agentes (Gaspar \& Pineda, 2012).12

Según Oclade, la reducción de la pobreza sería posible en la medida en que se alcanzara el objetivo central del desarrollo: lograr la dignidad humana antes que generar riqueza. La contribución religiosa significaba una "evangelización integral, inculturada y liberadora, partiendo de la realidad de los pobres, de su propia vida y religiosidad" (Olmedo Rivero, 2004, p. 96). La población de los valles interandinos, considerada marginal, "pobre y creyente" (Olmedo Rivero, 2004, p. 206) al mismo tiempo era valorada por su "cultura coya" y sus comunidades "cada vez menos pasivas y silenciosas, menos resignadas y sufridas" (Olmedo Rivero, 2004 , p. 7). ${ }^{13}$

\section{Derechos indígenas, agentes estatales y organismos multilaterales (1994-2007)}

Al compás de la ratificación progresiva de los tratados internacionales de derechos humanos de pueblos indígenas en Argentina - traducidos en reformas constitucionales, sanción de leyes y creación de organismos indigenistas-, Oclade incorporó estas herramientas a sus propuestas de formación y capacitación. Tal como recuerdan los actuales coordinadores y delegados de las organizaciones indígenas de segundo grado, Oclade promocionó el debate sobre la incorporación del artículo 75 inciso 15 de la Constitución Nacional, a principios de la década de 1990, cuando se trataba de un anteproyecto. De acuerdo con una extrabajadora de Oclade, hoy dirigente indígena de Iruya,

Oclade se subió al caballo en el momento cuando se empezó a hablar de derechos humanos, o sea hablando por el indígena

María Paula Milana, Emilia Villagra 
en adelante $[\ldots]$, hablando como los buenos de la iglesia sobre la discriminación, el maltrato, el maltrato de la mujer, de los indígenas (lideresa indígena de Iruya, entrevista, mayo 2013).

$\mathrm{El}$ intercambio de iniciativas y recursos entre Oclade y Endepa contribuyó a la formación de una camada de líderes indígenas en el campo de los derechos humanos que, vinculados con el movimiento indígena a nivel regional y nacional, lograron ejecutar iniciativas locales gestionando fondos provenientes de organismos multilaterales y del Estado nacional: “en esa lucha por las tierras, en ese ínterin es que nosotros conocemos mucha gente, muchos programas, así que ahí estamos nosotros con todo el tema de los contactos para los proyectos" (líder indígena de Iruya, exFinca Santiago, entrevista, diciembre de 2012).

Poniendo en valor memorias y saberes de generaciones pasadas, la lucha por el territorio se nutrió de estrategias gestadas en los debates por la defensa de los derechos colectivos y la habilitación de espacios para la participación indígena, en miras a operativizar estos corpus jurídicos. Por ejemplo, el Proyecto de Participación de los Pueblos Indígenas de 1996 fue un programa diseñado por Endepa, aprobado por la AIRA y financiado por la Secretaría de Desarrollo Social de la Nación (Carrasco, 2002). En Santa Victoria e Iruya fue instrumentado por Oclade, a cargo del padre Pedro Olmedo, en el cual
Se comienza a bajar información sobre los derechos indigenas a unas 223 comunidades de la Puna, Quebrada y Valles Salteños. Al mismo tiempo, consensuado por todos, se elaboró un documento, de voz indígena con fuertes denuncias, por los atropellos a la cultura y la apropiación indebida de sus tierras (Olmedo Rivero, 2004, p. 155). ${ }^{14}$

Entretanto, se profundiza lo que un dirigente kolla de Orán (exFinca San Andrés) ha llamado la "constitución de las comunidades ya como hecho jurídico" (asamblea del Qullamarka en Nazareno, agosto de 2014). ${ }^{15}$ Con el asesoramiento legal de Oclade, Endepa, AIRA y otros actores del movimiento indígena, comenzaron a tramitarse las personerías jurídicas para lograr su reconocimiento como comunidades y organizaciones indígenas, que finalmente las habilitaba a reclamar la propiedad comunitaria de las tierras. En este contexto, se recuerda que se sostenían "arduas discusiones con funcionarios estatales que consideraban que la Constitución Nacional no reconocía este tipo de organización" (Informe del Proyecto Kay Pacha, 2010, p. 23).

A fines de la década, lograron inscribirse las primeras personerías jurídicas nacionales kollas ${ }^{16}$ en el Registro Nacional de Comunidades Indígenas (Renaci): la Comunidad Indígena del Pueblo Kolla Finca Santiago (Res.633.-28/02/97), que logró la restitución de dicha finca como propiedad comunitaria en 1998; la Comunidad Indígena del Pueblo Kolla
14 Cursivas fuera del original.

15 Nos referimos a la autorización de personerias juridicas que las comunidades indigenas debieron obtener para lograr ser reconocidas por parte del Estado argentino.

${ }^{16}$ Las primeras personerias colectivas remitian a asociaciones vecinales de carácter provincial, como el caso de Finca El Potrero en 1993 (Hocsman, 2011). Desde 1994 buscarán inscribirse como personerias de comunidad indigena, en muchos casos superponiéndose a las anteriores.

\section{territarios 42-Especial}


${ }^{17}$ Creado en 1993 por la Secretaria de Agricultura, Ganadería y Pesca de la Nación y financiado por el Banco Mundial, el PSA fue un programa destinado a generar proyectos "pequeños” para campesinos. Luego mutó, en 2008, a la Llamada Subsecretaría de Agricultura Familiar (técnica PSA/SsAF, entrevista, noviembre 2011).

territarios

42-Especial
Tinkunaku (Res.4091.-26/10/97), que obtendría los títulos comunitarios con la expropiación de la Finca San Andrés en 2007 (figura 4), y la Asociación de Comunidades Aborígenes de Nazareno u OCAN (Res. 4084.- 30/12/1998), aun en lucha por los títulos de la Finca Santa Victoria.

Asimismo, desde fines del siglo pasado y principios del 2000 , el PSA $^{17}$ comenzó a implementarse en gran parte de los valles interandinos. Este programa fue relevante en su capacidad de dar respuestas a las demandas locales como actor externo, asesorando y poniendo sus técnicos a disposición en diversos espacios de encuentro.

En Nazareno, mediante el Proyecto de Desarrollo de Pequeños Productores Agropecuarios (Proinder), y en colaboración con la Universidad Nacional de Salta, el PSA estableció un convenio con la OCAN para efectivizar un diagnóstico sobre la situación de las tierras en el municipio, a fin de construir elementos jurídicos a favor de su lucha por los títulos comunitarios. En este contexto, la OCAN había logrado

Figura 4. Mapa de la organización Tinkunaku

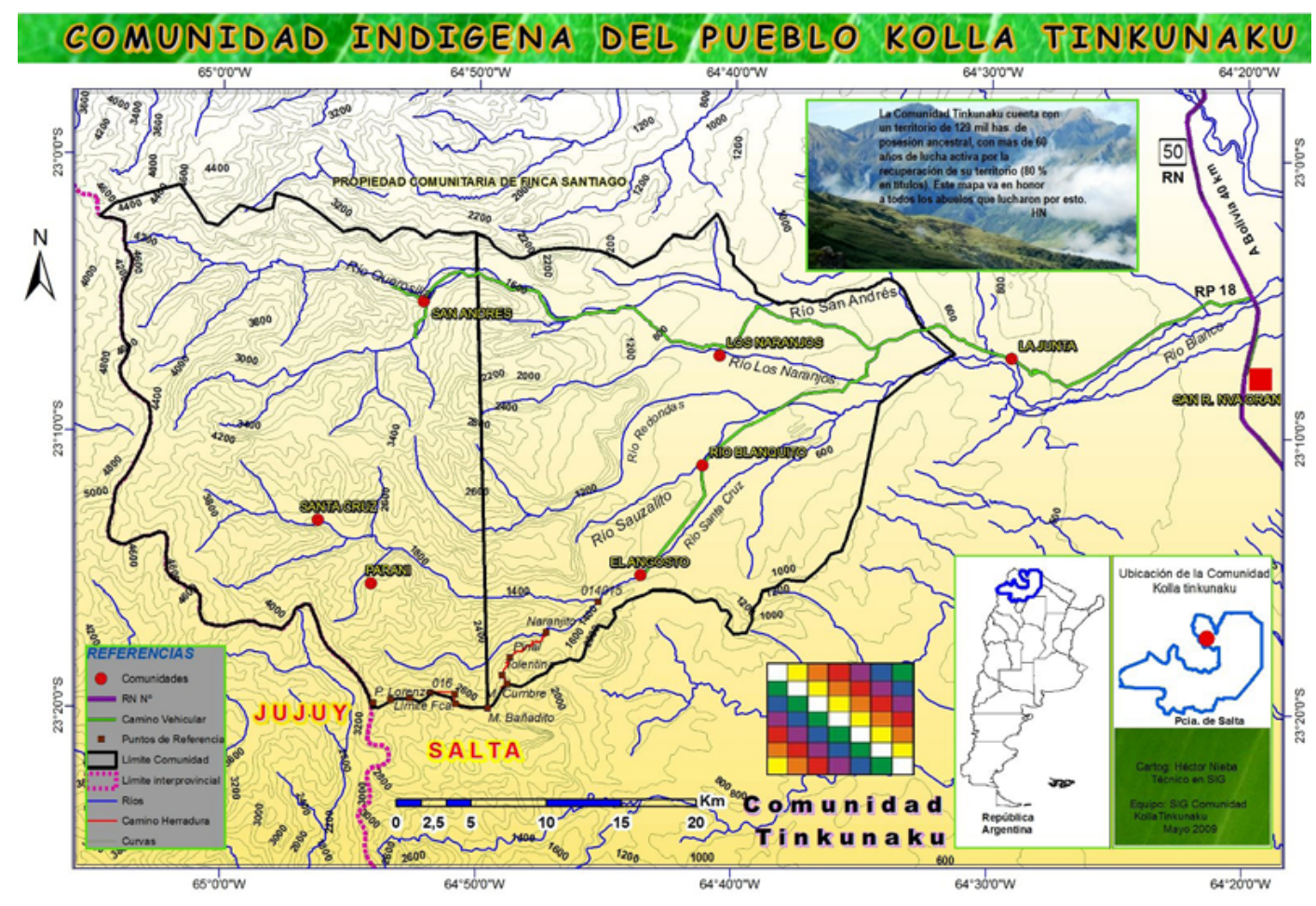

Fuente: https://comunidadtinkunaku.wordpress.com/mapas/ 
su reconocimiento jurídico y comenzaba a tener acceso a becas y proyectos del INAI. Acorde al primer objetivo planteado en su estatuto, que consiste en "promover el desarrollo integral", esta se vinculó con organizaciones no gubernamentales como Red Puna y Warmi-Sayajsungo. Mediante ellas, accedió a financiamiento internacional proveniente de entidades como la Agencia Alemana de Cooperación Técnica (GTZ) y el Fondo de Canadá para Iniciativas Locales (FCIL). Estas iniciativas se planteaban y debatían previamente en las asambleas de la OCAN. En estos encuentros, que comenzaban con la "oración del día", la "meditación de la palabra" o la "espiritualidad andina" en el patio de la Iglesia o el tinglado municipal, empezaba a marcarse una demanda cada vez mayor en torno a la capacitación en derechos e identidad indígena (Actas de OCAN, 1999-2004).

En Iruya, el PSA estuvo presente desde 1996 y se ejecutaba en articulación con otros programas de desarrollo. Su radio de acción se incrementó en los territorios donde se había logrado acceder a los títulos comunitarios, que permitió ejecutar una mayor cantidad de proyectos. Uno de los más relevantes fue el Proyecto de Desarrollo de Comunidades Indígenas (DCI). ${ }^{18} \mathrm{En}$ este contexto se creó el Consejo Indígena Kolla de Iruya (CIKDI) (figura 5), organización de segundo grado que desde el 2004 busca representar a las comunidades del departamento, intercambiar información y vincularse con organizaciones no gubernamentales e instituciones estatales, realizando seguimientos y evaluaciones a los proyectos "para el propio desarrollo que las comunidades quieren" (asamblea del CIKDI, abril de 2012).

En el marco de la consolidación del CIKDI y de acuerdo con la lectura realizada por un técnico local del PSA y actual líder indígena, el PSA evaluó:

la posibilidad de incorporar técnicos del lugar. Porque se había hecho una evaluación de que todos los trabajos de los técnicos en el territorio habían sido una experiencia que en todo caso no ha fortalecido la organización, a lo [sic] contrario: ha desorganizado (...) muchas pautas culturales que son propias de las comunidades (dirigente indígena de Iruya, Seminario de Políticas Públicas organizado por la Tecnicatura en Desarrollo Indígena, Humahuaca, noviembre de 2014).

De esta forma, el programa incorporaría a partir de 2007 a los llamados técnicos idóneos en sus equipos territoriales, es decir, líderes y miembros de las organizaciones que eran capacitados en diversas áreas de trabajo, respondiendo así a una demanda de las organizaciones que había comenzado en Iruya y luego se expandió a otros lugares de los valles interandinos como Nazareno, Santa Victoria Oeste y los Toldos.

Previamente, en 2003, el PSA, Oclade y Endepa incentivaron la realización del primer acercamiento entre las comunidades
18 Acorde a las disposiciones del INAI (2004) para promover "la participación indigena a través del apoyo técnico y financiero para la ejecución de proyectos de desarrollo sustentable con identidad" y con el asesoramiento técnico y financiamiento por parte del Banco Mundial, el proyecto DCI se ejecutó en las comunidades kollas de Finca Santiago desde el año 2000 hasta 2006 (Carrasco, Sterpin \& Weinberg, 2008). Este proyecto se efectivizó en carácter de "donación" del Banco Mundial al Fondo para el Desarrollo Internacional, en pos de realizar un programa de fortalecimiento para el desarrollo indigena a fines de la década del noventa.

\section{territarias 42-Especial}

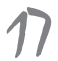


Figura 5. Comunidades con personería jurídica que integran el Consejo Indígena Kolla de Iruya (CIKDI)

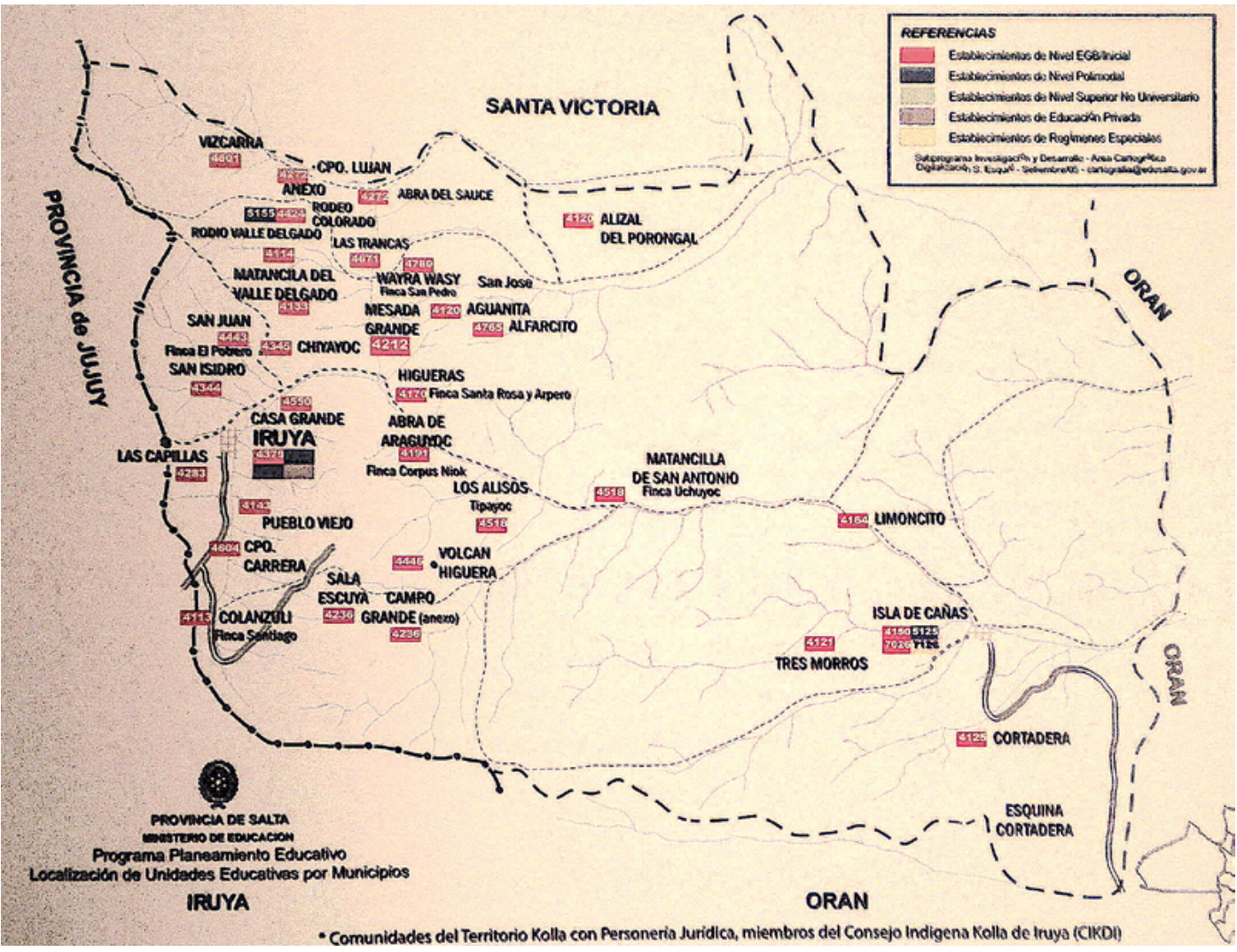

Fuente: cartilla pedagógica del Colegio Secundario del Municipio de Iruya (2010).

del departamento de Santa Victoria Oeste: el Encuentro de Comunidades Aborígenes de Nazareno y Santa Victoria. Con el objetivo de trabajar conjuntamente para lograr los títulos comunitarios de la Finca Santa Victoria, se organizaron capacitaciones, disertaciones y tratamiento de las legislaciones de derechos indígenas, además de la participación de funcionarios del Estado y una creciente presencia de comunidades del municipio de los Toldos. En estos encuentros participó el abogado Rodrigo Solá, actualmente miembro de Endepa y de la Asociación de Abogados de Derecho Indígena (AADI), quien, en el marco de un convenio entre la OCAN, el PSA y la Universidad Nacional de Salta (UNS), elaboró el proyecto Kay Pacha financiado por el INAI, con el que logró trazar el plano de mensura que incluyó a 
Figura 6. Plano de mensura de la Finca Grande de Santa Victoria, logrado mediante el Proyecto Kay Pacha y aprobada por el Estado provincial

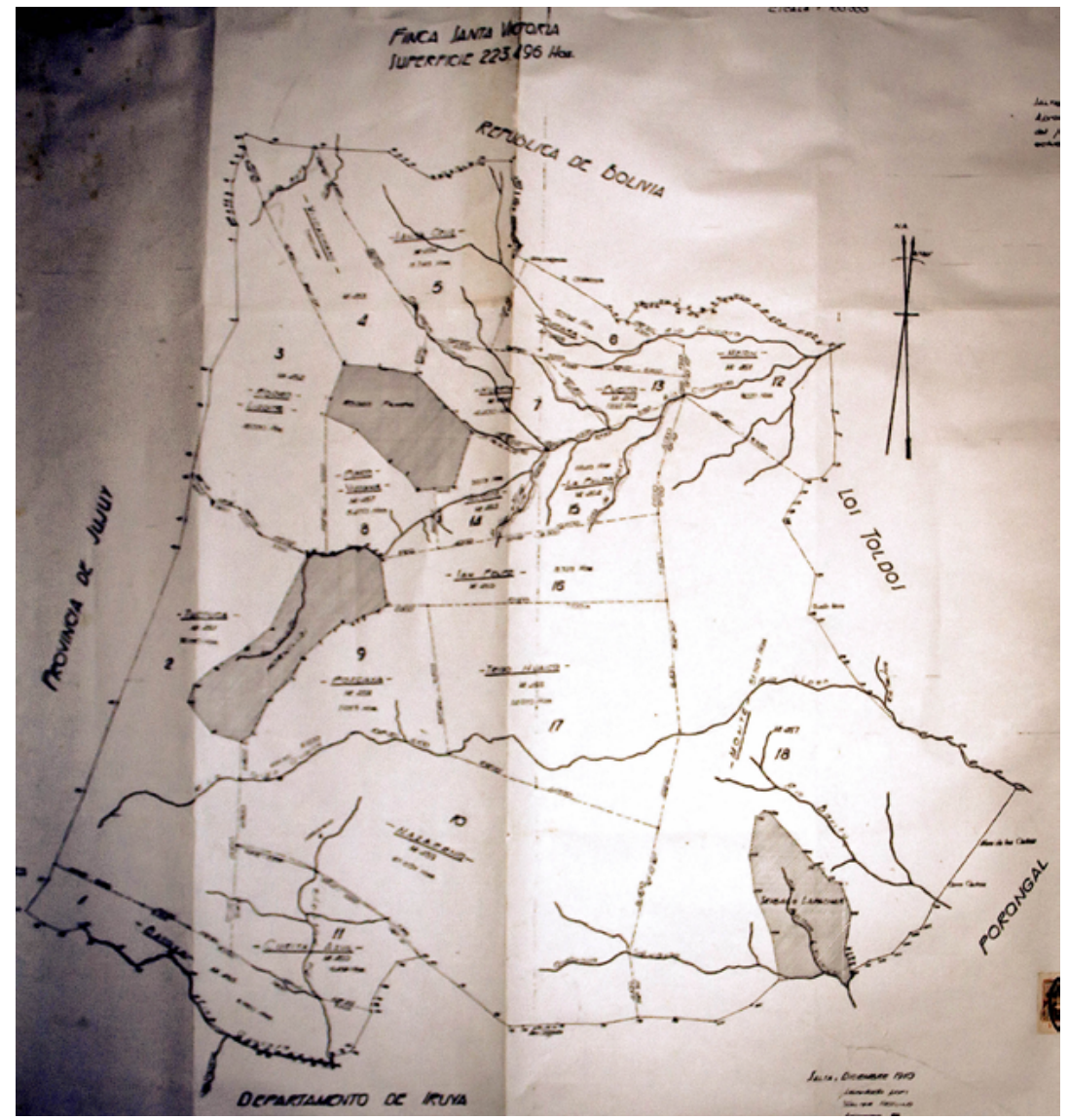

Fuente: fotografía propia, asamblea del Qullamarka, Rodeo Colorado, Iruya, noviembre 2014.

todas las comunidades de la Finca Grande de Santa Victoria (figura 6) y un relevamiento de la situación histórica y jurídica de ellas.

Diferentes testimonios expresan que estos encuentros permitieron la convergencia y construcción colectiva de lecturas políticas y estratégicas; asimismo, estos agilizaron la conformación de la Unión de Comunidades Aborígenes Victoreñas (UCAV), organización de segundo grado de Santa Victoria. Las iniciativas para constituir un frente de lucha común entre las comunidades del municipio se veían limitadas por la línea política partidaria, liderada por Alcides Ontiveros. Se trata tersitorios 42-Especial 
de quien ejerció la intendencia de Santa Victoria durante veinte años (1983-2003), cuya gestión es recordada como partícipe del sistema de explotación de trabajo en los ingenios azucareros y ha sido denunciada por corrupción, nepotismo, violencia física y discriminación racial hacia los pobladores. En estas instancias, las comunidades victoreñas se movilizaron cortando el acceso al pueblo para manifestarse en contra del intendente, quien "huye por el monte" (Copenoa, 9 de diciembre de 2003). De esta forma, la UCAV se propuso denunciar prácticas clientelares y violentas del gobierno provincial y municipal, las cuales dividían a las comunidades del municipio.

\section{Caravanas del pueblo kolla: la consolidación del territorio Qullamarka}

Un antecedente inmediato a la constitución de Qullamarka fue el sexto Encuentro de Comunidades Aborígenes de Nazareno y Santa Victoria, en 2006, en el cual participaron dirigentes de Iruya. En esa instancia, informaron sobre una orden judicial de desalojo hacia dos de las comunidades iruyanas, por lo que se propuso la realización de una caravana para exigir el cese de las amenazas y demandar la aprobación de planos de mensura de dichas comunidades (Indymedia Argentina, 2006). Considerando la urgencia, el encuentro acordó acompañar la medida, la cual se denominó Jornada de Movilización y Protesta del Pueblo Kolla de
Salta, recordada como la primera marcha del Qullamarka demandando la regularización de los títulos y el cumplimiento efectivo de los derechos constitucionales del pueblo kolla.

De esta movilización, organizada por dirigentes de Iruya, Nazareno y Santa Victoria oeste, se recuerda cómo logró la alianza con otros líderes kollas de la organización Tinkunaku de Orán, quienes eran pioneros en sus luchas, sus trayectorias de confrontación con el Estado y denuncia ante el incumplimiento de sus derechos colectivos. Esta primera marcha trazó un itinerario que sería replicado en otras posteriores, con concentraciones que partían desde la localidad de La Quiaca o Humahuaca, en la provincia de Jujuy, para recorrer más de 500 kilómetros hasta llegar a la capital de la provincia de Salta.

A fines de 2006, en el noveno encuentro de comunidades realizado en Nazareno, se reemplazó su nombre por Kollamarkanakuy, que en lengua quechua significa reunión del pueblo kolla. Se buscaba así responder a la creciente convocatoria y participación del encuentro, ya que además del CIKDI se habían incorporado la organización Tinkunaku y la Comunidad Indígena Alta Cuenca del Río Lipeo Los Toldos (CIACRL). Durante este encuentro, se acordó realizar las Segundas Jornadas de Movilización y Protesta del Pueblo Kolla de Salta, en abril de 2007 (Indymedia Argentina, 2007).

Esta segunda movilización recuperó el petitorio de la marcha anterior, expresando 
que se había incumplido el compromiso asumido por el gobierno luego de dicha jornada, en el que se enfatizó en cuestiones como la infraestructura hospitalaria y educativa; sumando a otras exigencias como el título comunitario de la exFinca San Andrés reclamada por la comunidad de Tinkunaku, el cuestionamiento al funcionamiento del Instituto Provincial de Pueblos Indígenas de Salta (IPPIS) y la exigencia de su inmediata normalización, demandando que cese la situación de doble personería jurídica en las comunidades, la cual entre otras dificultades había provocado la aprobación de un convenio minero con el supuesto consentimiento de representantes de las comunidades. Este petitorio, entregado en la legislatura provincial y luego en la Casa de Gobierno de Salta, logró ser discutido por un grupo de delegados de las organizaciones en una reunión con funcionarios provinciales.

Tres meses más tarde, como resultado de la marcha y posteriores presiones, se entregó la escritura de propiedad comunitaria de la exFinca San Andrés a la comunidad de Tinkunaku, junto al inicio de un trámite necesario para los títulos de las comunidades amenazadas de Iruya. A esto se sumaron otros acuerdos como cancelar la construcción de una hostería provincial en Santa Victoria oeste y el compromiso de avanzar con la regularización de los títulos comunitarios de la Finca Santa Victoria, correspondientes a las demandas de Santa Victoria y Nazareno.
En diciembre de 2007, en Santa Victoria oeste, el nombre del encuentro volvió a cambiar a modo de adecuarse y respetar su nombre en quechua como $4^{\circ}$ Qullamarka Tinkunakuy. Se decidió crear un espacio formal de encuentro que articulara y fortaleciera a las organizaciones, con una periodicidad de reuniones cada tres meses y que enmarcara el territorio. De esa manera, se consolidó el Qullamarka: Coordinadora de Organizaciones y Comunidades Kollas Autónomas de Salta.

En su acta constitutiva quedó establecido su objetivo: "constituirse como herramienta de ejercicio en búsqueda de la autonomía sobre nuestros territorios y recursos naturales, en cumplimiento del derecho indígena". Su representación estaría dada por los coordinadores de cada organización miembro, en ese entonces con la participación de Nazareno, Santa Victoria, Iruya y Orán, invitando a las demás organizaciones a integrarse dentro del marco ya establecido. Esto impulsó la participación definitiva de las comunidades de la localidad de Los Toldos, agrupadas también como una organización de segundo grado.

De esta manera, Qullamarka encubre un significado tripartito en términos sociopolíticos, ya que al mismo tiempo designa la organización misma (la Coordinadora de Organizaciones y Comunidades Kollas Autónomas de Salta), el territorio sobre el cual ejerce su jurisdicción (el territorio Qullamarka, que aquí delimitamos bajo la territarios 42-Especial 
categoría espacial de valles interandinos) y las asambleas (los encuentros Qullamarka Tinkunakuy) en los que se definen intereses comunes y se consensuan formas de luchar. Su proyecto plantea que, en la heterogeneidad de los colectivos que la componen, la identidad kolla y las luchas - por el territorio, el reconocimiento de derechos y la aplicación adecuada de políticas públicas - forman parte de un mismo entramado. En este sentido, la organización se ha conformado como elemento de cohesión e identificación, de acuerdo con sus integrantes: "por ser parte del Qullamarka somos todos hermanos, y el territorio es uno solo" (asamblea del Qullamarka, febrero 2013, Colanzulí, Iruya) (figura 7).

\section{Reflexiones finales}

En este artículo, partimos de la pregunta acerca de las circunstancias históricas y políticas en las que se constituyeron las organizaciones indígenas kollas en los valles interandinos. Para ensayar una respuesta, referimos brevemente a los procesos mediante los cuales, desde mediados y fines de los años ochenta, se consolidaron y visibilizaron diferentes colectivos indígenas en Argentina, con énfasis en la provincia de Salta y las disputas por la propiedad de las tierras. Luego establecimos una delimitación temporal y contextual diferenciada en dos recortes analíticos: el primero, desde 1983 hasta mediados de la década de 1990, con el fin de identificar una etapa inicial de los procesos organizativos. En este periodo se hace visible el tejido de una red conformada por diversos actores externos, con la posterior incorporación de recursos locales y técnicos idóneos, miembros de las comunidades indígenas cuyos saberes situados eran retomados para adecuar la implementación de numerosos programas y proyectos de desarrollo. Esta mirada nos permite comprender cómo estas dinámicas de intervención no transcurrieron netamente desde afuera, sino que se desplegaron en un complejo proceso de negociación, en el que a nivel local se demandaba infraestructura y recursos, pero a la vez las intervenciones eran mediadas por las propias comunidades.

Retomando nuestro recorte analítico, un segundo tramo se enmarca en los procesos de juridización indígena a niveles internacionales, nacionales y provinciales, que remiten a las instancias en las que se consolidan las organizaciones y se inician una serie de encuentros que pueden considerarse la procedencia inmediata de la creación del Qullamarka en 2007. En este sentido, el espacio que actualmente las organizaciones producen y defienden como territorio Qullamarka, ya estaba siendo delineado por las trayectorias de quienes inicialmente conformaron las organizaciones de segundo grado, entre otras cuestiones, ideando proyectos, gestionando subsidios y creando estrategias de lucha diversas para dar continuidad a las demandas y reclamos planteados por los miembros de las comunidades. 
Figura 7. Territorio del Qullamarka

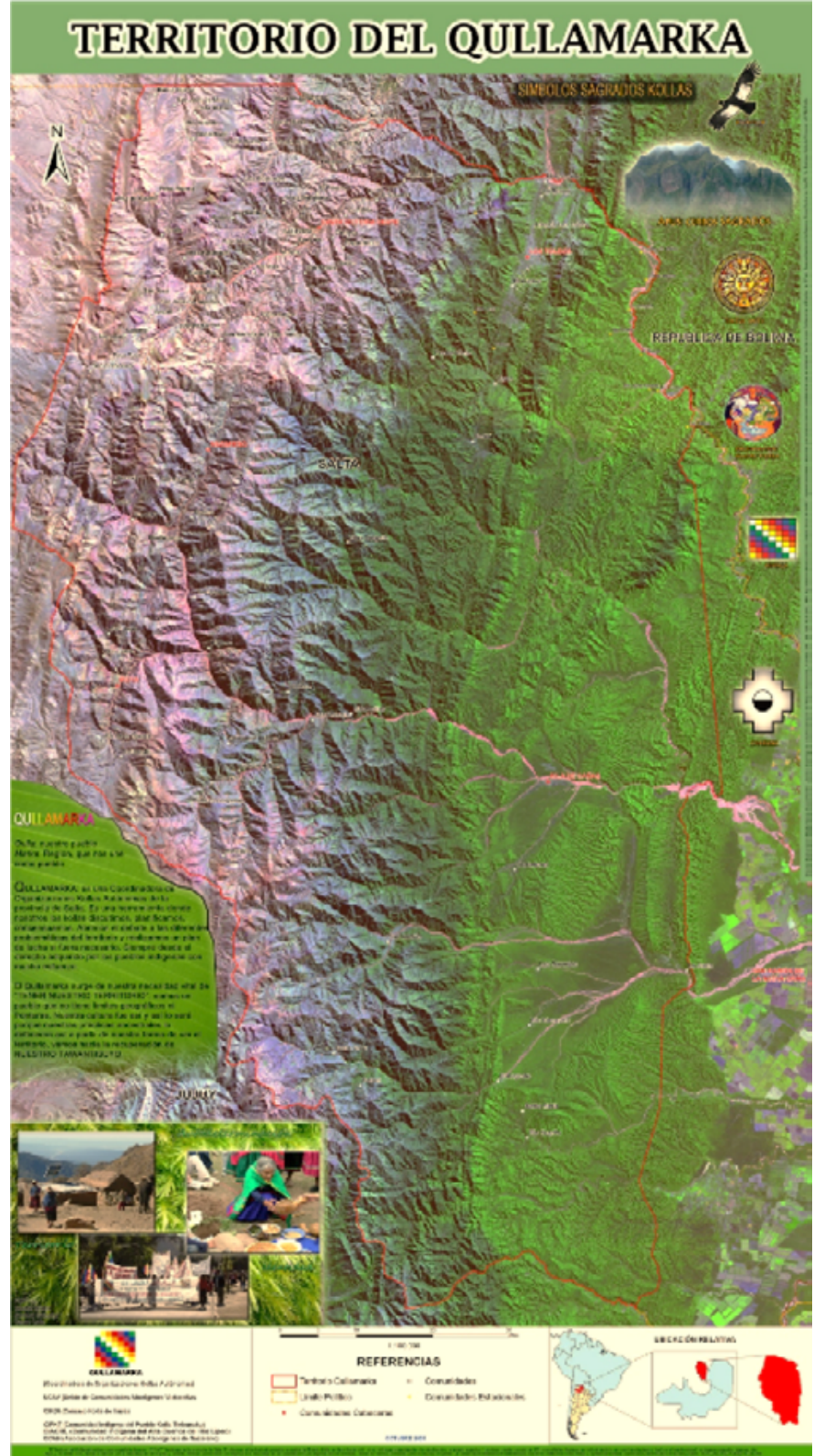

Fuente: elaborado por Héctor Nieba exdirigente de Tinkunaku y trabajador de Parques Nacionales.

territarias

42-Especial

23

ENTRE PRÁCTICAS DE INTERVENCIÓN Y PROYECTOS DE DESARROLLO 
Tanto en Iruya como en Santa Victoria, actores como Oclade y Endepa pueden considerarse centrales en la catalización de algunos aspectos de los procesos organizativos indígenas. Esto puede entreverse en el reconocimiento generalizado de su labor pastoral que empieza a distinguir "pertenencias originarias" en el conjunto de los pobladores de los valles interandinos:

Gran parte de las comunidades indígenas de hoy o de todo el Qullamarka al menos, antes de ser Qullamarka, eran impulsadas por este lado [Oclade] (...) las organizaciones iban cada una por su lado, primero comunidades, después se fueron armando las organizaciones como la OCAN, la UCAV que fueron las primeras, después nos agregamos nosotros, después se agregó Tinku [Tinkunaku], después al último (...) se agregó Baritú. El Qullamarka nació en Nazareno y Victoria (lideresa indígena, entrevista, mayo 2013).

En coordinación con otras organizaciones, Oclade fue clave en la "misión" de lograr el empoderamiento de los sujetos intervenidos, posibilitando la construcción de un sujeto colectivo "liberado y autónomo". Por su parte, el PSA fortalecería esta tarea, aunque desde el asesoramiento en términos productivos y jurídicos: gestionando múltiples proyectos para la mejora de la producción para la autosubsistencia y diseñando diagnósticos a través de metodologías participativas que ponían el acento en la recuperación de prácticas, saberes y técnicas tradicionales. Muchos de estos proyectos requerían del aporte de las comunidades beneficiarias en mano de obra y debían ser rendidos, en general, por sus miembros.

Los actuales líderes de las organizaciones de Iruya y Santa Victoria reconocen el rol de Oclade y del PSA en los momentos previos de la consolidación interorganizacional e intraorganizacional, como los Encuentros de Comunidades desde 2003. En esta dirección, diferentes testimonios permiten entrever la genealogía del Qullamarka, en los que se expresa su nacimiento a partir de la vinculación organizativa entre Nazareno y Santa Victoria, "después sabían que nosotros nos estábamos organizando y vinieron la parte de Tinkunaku, también algunos de Jujuy (...) Ahí es cuando decidieron formar la organización de toda esta zona y llamarlo como Qullamarka" (líder indígena, exintendente de Nazareno, entrevista, Nazareno, agosto de 2014).

También se expresa que, al constituirse como una coordinadora conformada por organizaciones agrupadas como pueblo kolla, con trayectorias heterogéneas, la filiación con Oclade fue problematizada. En este sentido, algunas voces reconocen que «Oclade fue parte de muchos de los procesos de OCAN, de las personerías jurídicas. Les parece que Qullamarka es como un "hijo", cuya presencia en los territorios disminuyó al cumplirse su objetivo de promover "organizaciones independientes" " (Asamblea del Qullamarka en Colanzulí, 
Finca Santiago, febrero de 2013). En esta línea se resalta su positividad, aunque marca distancias y establece un "nosotros" distinto.

Por un lado, observamos que estas iniciativas, fuertemente permeadas por lógicas de promoción y desarrollo, están limitadas por la construcción de sujetos productivos que deben "integrarse" para mejorar sus condiciones de vida. Esto se enmarca en un modelo multicultural y neoliberal que durante el periodo comprendido se asentó en normativas y directrices ideadas por bancos y agentes de cooperación internacional. La emergencia de las organizaciones acontecería en un contexto en el cual la nueva reorientación de las políticas sociales sería apoyada económicamente por organismos multilaterales durante las sucesivas presidencias argentinas de Carlos Saúl Menem (1989-1999).

En este sentido, la forma de interpelación hacia los sujetos en los valles interandinos remite a dispositivos de gobierno que fueron mutando al compás de ciertos saberes considerados hegemónicos e instituidos como legítimos, que han intervenido en el espacio territorial clasificando a sus pobladores según la coyuntura como pobres estructurales, beneficiarios, campesinos/indígenas o sujetos de derecho colectivo, pero fundamentalmente como sujetos que deben hacerse cargo de su propio desarrollo. Creemos que estas formaciones convergen en la experticia en búsqueda de financiamiento externo y en proyectos y lógicas de desarrollo que contribuyen a perpetrar sentidos del "indio permitido" (Hale, 2004).

Por otro lado, estos procesos también habilitaron la eventualidad de legitimar saberes y luchas singulares, dando lugar a nuevas condiciones que permitieron que otros saberes locales entraran en juego, aquellos relegados o considerados inferiores (Foucault, 2000). Fundamentalmente, la reivindicación de estos saberes ha permitido delinear otra forma de hacer y pensar "la política" desde las organizaciones indígenas de los valles interandinos. Recurriendo al uso de discursos en torno al desarrollo y a los derechos colectivos, la disputa comenzó a planearse en términos de representación en pos de permitir que los mismos actores pudieran proponer otras modalidades de desarrollo, legitimadas por las propias comunidades.

Esta es la apuesta política del Qullamarka, gestada por y entre las organizaciones kollas que actualizaron un conjunto de relaciones sociales en los valles interandinos, anudando memorias compartidas sobre vivencias de despojos y luchas por el territorio, tejiendo redes que lo trascienden y nutren de forma singular la visibilidad de las demandas indígenas en la provincia de Salta.

\section{Referencias}

Álvarez Leguizamón, S. (2008). Pobreza y desarrollo en América Latina. Salta: EUNSA. territarios 42-Especial 
Álvarez Leguizamón, S., \& Muñoz, S. (2010). Categorías nativas, nominaciones de la alteridad y voces autorizadas en la invención de "la Sociedad" y "la Tradición Salteña": literatura y dialectología. En S. Álvarez Leguizamón (Comp.), Poder y salteñidad: saberes, politicas y representaciones sociales (pp. 115-133). Salta: CEPIHA.

Álvarez Leguizamón, S. (2015). Neocolonialismo, capitalismo, pobreza y resistencias. Rosario: Prohistoria Ediciones.

Briones, C. (1998). La alteridad del cuarto mundo. Una deconstrucción antropológica de la diferencia. Buenos Aires: Ediciones del Sol.

Briones, C., \& Ramos, A. (2010). Replanteos teóricos sobre lachas acciones indígenas de reivindicación y protesta: aprendizajes desde las prácticas de reclamo y organización mapuchetehuelche. En G. Gordillo, \& S. Hirsch (Comps), Movilizaciones indigenas e identidades en disputa en Argentina: historias de invisibilización y re-emergencia (pp. 39-78). Buenos Aires: Flacso-Editorial La Crujía.

Buliubasich, C. (2013). La política indígena en Salta. Límites, contexto etnopolítico y luchas recientes. RUNA, 34, 59-71.

Campi, D., \& Lagos, M. (1995). Auge azucarero y mercado de trabajo en el Noroeste argentino, 1850-1930. En J. S. Riquer, J. C. Grosso y C. Yuste (Comps). Circuitos mercantiles y mercados en Latinoamérica. Siglos XVIII y
XIX (pp. 179-208). México: Instituto de Investigaciones J. Mora.

Carrasco, M. (2002). El movimiento indigena anterior a la reforma constitucional y su organización en el Programa de Participación de Pueblos Indigenas. Recuperado de http://hdl.handle. net $/ 2152 / 4069$

Carrasco, M., Sterpin, L., \& Weinberg, M. (2008). Entre la cooperación y la asistencia: un análisis de la incidencia del apoyo económico internacional en el movimiento indígena en Argentina. Avá, (12), 09-26.

Cladera, J. L. (2006). Implicancias de la apropiación comunitaria de la tierra sobre las actividades de subsistencia de la Comunidad Kolla de Finca Santiago (Provincia de Salta), (Tesis de Licenciatura en Ciencias Antropológicas, Universidad de Buenos Aires, Buenos Aires).

Domínguez, D. (2008). ¿La trashumancia de los campesinos kollas: hacía un modelo de desarrollo sustentable? En G. Alvarado Merino et al. (Eds.), Gestión ambiental y conflicto social en América Latina (pp. 137-191). Buenos Aires: Clacso.

Escobar, A. (2003). Mundos y conocimientos de otro modo. El programa de investigación de modernidad/colonialidad latinoamericano. Tabula Rasa, (1), 51-86.

Foucault, M. (1992). Microfísica del poder. Madrid: La Piqueta. 
Foucault, M. (2000). Defender la sociedad: curso en el Collège de France (1975-1976). Buenos Aires: Fondo de Cultura Económica.

Gaspar, J., \& Pineda, D. (2012). Saberes sobre sanidad animal y el mejoramiento de la producción ganadera en santa victoria oeste. Ponencia presentada en las XVI Jornadas Nacionales de Extensión Rural y VIII del Mercosur.

González, D. G. (2013). Conflictos por el territorio en la comunidad indigena del pueblo kolla tinkunaku, (Tesis de maestría, Universidad Nacional de Buenos Aires, Buenos Aires).

Gordillo, G., \& Hirsch, S. (2010). Movilizaciones indigenas e identidades en disputa en Argentina: historias de invisibilización y re-emergencia. Buenos Aires. Flacso. Editorial La Crujía.

Guber, R. (2011). La etnografía. Método, campo y reflexividad. Bogotá: Grupo Editorial Norma.

Hale, C. (octubre, 2004). El protagonismo indigena, las politicas estatales y el nuevo racismo en la época del 'indio permitido'. Ponencia presentada en "Construyendo la paz: Guatemala desde un enfoque comparado," organizado por la Misión de Verificación de las Naciones Unidas en Guatemala (Minugua).

Hocsman, D. (1997). De la zafra a la tierra kolla. Acerca de la construcción social de la Identidad en los valles intermontanos de la cordillera oriental (San Isidro-Salta). Ponencia presentada en el V Congreso de Antropología Social, La Plata.

Hocsman, D. (2011). Estrategias territoriales, recampesinización y etnicidad en los Andes argentino. Xochimilco: Clacso - División Ciencias Sociales y Humanidades Publicaciones-Universidad Autónoma Metropolitana.

Lanusse, P., \& Lazzari, A. (2005). Salteñidad y pueblos indígenas: continuidad y cambio en identidades y moralidades. En C. Briones, (Comp.). Cartografias argentinas. Politicas indigenistas y formaciones provinciales de alteridad (pp. 185-209). Buenos Aires: Antropofagia.

Lefebvre, H. (2013). La producción del espacio. Madrid: Capitán Swing.

Madrazo, G. B. (1982). Hacienda y encomienda en los Andes: la Puna argentina bajo el marquesado de Tojo, siglos XVII a XIX. Buenos Aires: Fondo editorial.

Milana, M. P. (2014). "La cuestión del "trabajo” en el campo de las politicas sociales “inclusivas” (Argentina, 2003-2013) y las prácticas del "trabajo a pulmón”. El caso de Iruya. (Tesis de Licenciatura en Antropología, Universidad Nacional de Salta, Salta).

Milana, M. P., \& Villagra, E. (2018). Comunicación indígena en el noroeste argentino: el caso de la radio FM OCAN (Salta, Argentina). Anuario Electrónico de Estudios en Comunicación Social “Disertaciones", 11(2), 128-142. https://doi.org/10.12804/revistas. urosario.edu.co/disertaciones/a.5722 territarios 42-Especial 
Occhipinti, L. (2015). Faith based organizations and the neoliberal state: creating resistance in Northern Argentina. Journal of International and Global Studies, 7(1).

Olmedo Rivero, J. (2004). Pedro Olmedo: un obispo como la gente. Misioneros Claretianos, Prelatura de Humahuaca. Salta: Artes Gráficas Crivelli.

Quiroga Mendiola, M., Saravia, A., \& Bilbao, L. (2006). Desarrollo local, instituciones y territorio en Iruya, provincia de Salta. En M. Manzanal, G. Neiman, \& M. Lattuada, (Comps.), Desarrollo rural: Organizaciones, instituciones y territorios (pp. 375-394). Buenos Aires: Fundación Centro Integral Comunicación, Cultura y Sociedad (CICCUS).

Radovich, J. \& Balazote, A. (1992). La problemática Indigena. Estudios antropológicos sobre poblaciones indigenas de la Argentina. Buenos Aires: Centro Editor de América Latina.

Reboratti, C. (2009). El Alto Bermejo. Realidades y conflictos. Buenos Aires: Editorial La Colmena.

Restrepo, E. (2008). Cuestiones de método: "eventualización" y problematización en Foucault. Revista Tabula Rasa, (8), 111-132.

Sabio Collado, V., \& Milana, P. (2018). El devenir de la "lucha". La política colectiva de organizaciones indígenas en perspectiva (Salta, Argentina).
Memoria Americana. Cuadernos de Etnohistoria, 6(2), 125-142.

Teruel, A. (2016). El marquesado del Valle de Tojo. Patrimonio y mayorazgo en Bolivia y Argentina. Revista de Indias, 77(267), 379-418.

Torres, M. \& Torres, A. (2010). ¿Por qué callan si nacen gritando? Poder, accesibilidad y diferencias culturales en Salud. Iruya, 1997-2008. Formosa: Editorial Endepa, Equipo Nacional de Pastoral Indígena.

Villagra, E., \& Milana, M. P. (2019). Trayectorias de luchas y memorias subalternizadas. El caso de la Organización de Comunidades Aborigenes de Nazareno (Salta, Argentina). Ponencia presentada en el $1^{\circ}$ Congreso Latinoamericano de Ciencias Sociales, Universidad Nacional de Villa María, Córdoba.

Villagra, E. (2016). Queremos que la gente no pueda vivir sin la radio. Procesos de gestión y de construcción de contenidos. El caso de Organización de Comunidades Aborigenes de Nazareno (OCAN). Salta, 2014-2016. (Tesis de Licenciatura en Comunicación Social, Universidad Nacional de Salta, Salta).

Weinberg, M. (2004). Identidad y Politica. Formas de organización en la Comunidad Kolla de Finca Santiago (Iruya-Salta). (Tesis de Licenciatura en Ciencias Antropológicas, Universidad de Buenos Aires, Buenos Aires).

María Paula Milana, Emilia Villagra 


\section{Otras fuentes consultadas}

Agencia de Noticias Copenoa (9 de diciembre de 2003). Santa Victoria Oeste: Pobladores cortan los accesos del pueblo. Recuperado de https://clajadep.lahaine.org $/ ? \mathrm{p}=2192$

Agenda Pública (1 de diciembre de 2008). Fundación Oclade: 25 años de trabajo junto a las comunidades de Quebrada y Puna. Recuperado de http://agendapublicadigit.blogspot.com/2008/12/ fundacion-oclade-25-aos-de-trabajo_01.html

Colegio Secundario del Municipio de Iruya $\mathrm{N}^{\circ} 5058$ "Senador Emilio E. Correa" (2010) Nuestros derechos como pueblo originario kolla. Orientadores Interculturales del Consejo Indígena Kolla de Iruya. Programa de Educación Intercultural. Ministerio de Educación de la Nación, Ciencia y Tecnología.

Convenio 169 de la OIT (1989). Recuperado de https://www.ilo.org/ wcmsp5/groups/public/---americas/--ro-lima/documents/publication/ wcms_345065.pdf

Eizayaga, A. (febrero 1 de 2015). Pedro Olmedo: «Hay una violencia institucional que generan los dirigentes y que impregna las capas de abajo». Diario La Nación. Recuperado de https:// www.lanacion.com.ar/1764239-pedro-olmedo-hay-una-violencia-institucional-que-generan-los-dirigentesy-que-impregna-las-capas-de-abajo
Indymedia Argentina. (2006). Jornadas de movilización y protesta del pueblo kolla de la provincia de Salta. Recuperado de http://archivo.argentina.indymedia. org/news/2006/03/386710.php

Indymedia Argentina. (2007). Comunidades indigenas marcharon por el cumplimiento de sus derechos. Recuperado de http://archivo.argentina.indymedia. org/news/2007/04/509952.php

Informe final del Proyecto "Kay Pacha". (2010). Análisis de las condiciones históricas, legales y registrales de las fincas de Santa Victoria y Mecoyita para la regularización de la situación dominial de sus tierras. Salta. Entidad subsidiante: Instituto Nacional de Asuntos Indígenas - Ministerio de Desarrollo Social. Expte. $N^{\circ} 50.290 / 2005$.

Instituto Nacional de Estadísticas y Censos de la República Argentina (1991). Censo Nacional de Población $y$ Vivienda. Recuperado de https:// www.indec.gob.ar/indec/web/ Nivel4-Tema-2-41-136

Instituto Nacional de Estadísticas y Censos de la República Argentina (2010). Censo Nacional de Población, Hogares y Viviendas. Recuperado de https:// www.indec.gob.ar/indec/web/ Nivel4-Tema-2-21-99

Registro Nacional de Comunidades Indígenas (2012). Resolución 115/2012. Recuperado de http://servicios. infoleg.gob.ar/infolegInternet/ anexos/195000-199999/197896/ norma.htm territarios 42-Especial 29 